\title{
HOMENAGEM AO PROFESSOR TITULAR GUIDO FERNANDO SILVA SOARES
}

Umberto Celli Junior"*

Falar da vida e da obra de um homem da grandeza do Professor Guido Fernando Silva Soares não é tarefa fácil. Ainda mais porque, até bem pouco, estava ele aqui conosco e a tristeza com seu desaparecimento prematuro cala fundo em nossas almas. Lembro-me de que, no ano passado, no $2^{\circ}$ Congresso de Direito Internacional, realizado nesta mesma bonita cidade de Curitiba, aqui estava ele a encantar uma imensa platéia com sua vasta cultura, sabedoria e experiência.

Sua habilidade e talento no trato com as pessoas, seu humor refinado, sua sensibilidade na percepção das necessidades e dos problemas alheios, sua insuperável capacidade de ouvir e de aconselhar, bem como seu despojamento, logo o levaram a compreender que tinha uma importante missão a cumprir. Uma missão que transcendia as ambições pessoais mais imediatas. Com seu caráter forjado em uma inabalável fé cristã e católica (conhecia como poucos a doutrina do cristianismo, passando de Santo Agostinho a São Thomaz de Aquino e era fervoroso devoto de Nossa Senhora Aparecida e de Nossa Senhora de Fátima), sempre teve como objetivo servir e ajudar às pessoas e ao seu País que tanto amava.

Profundo conhecedor de idiomas (Latim, Português, Francês, Italiano, Alemão e Russo), das artes, da história, da geografia, da literatura, da poesia, da música clássica (Debussy era um de seus favoritos, especialmente quando tocava piano com a mesma sensibilidade com que transmitia seus conhecimentos), buscou inicialmente na carreira diplomática um meio de servir a seu País. Corajoso. destemido, fiel seguidor de seus princípios democráticos, aceitou sem hesitação à convocação para servir na Embaixada do Brasil em Moscou, na ex-União Soviética.

Vivia-se no Brasil sob o domínio de uma ditadura militar (à qual ele jocosamente sempre se referia como a "Revolução Gloriosa e Redentora") e logo seu gesto foi confundido com o de um adepto e simpatizante do regime soviético. Justo ele, um incansável defensor da liberdade, da democracia e dos Direitos Humanos. Começou, então, a ser implacavelmente perseguido a ponto de ser forçado a retirar-se da carreira.

Discurso proferido durante a abertura do $3^{\circ}$ Congresso de Direito Internacional realizado na cidade de Curitiba, de 24 a 27/08/2005.

-. Professor Doutor do Departamento de Direito Internacional da Faculdade de Direito da Universidade de São Paulo. 
Depois de uma longa batalha política, administrativa e judicial (que teve o inestimável apoio do professor Vicente Marotta Rangel, dentre outros ilustres brasileiros), conseguiu, muitos anos mais tarde, e quando já havia descoberto, felizmente para todos nós, sua verdadeira vocação, ser reintegrado, mas, apenas, por uma questão de honra e de restabelecimento da justiça. Em 1993, foi agraciado com o titulo de Comendador da Ordem do Rio Branco, do Ministério das Relações Exteriores.

A perseguição política não abalou suas convicções e princípios. Pelo contrário, reforçou-os. Ele encontrou na Universidade o caminho para a realização plena de sua missão e vocação. Dedicuu-se como poucos a essa extraordinária missão que é a de ensinar e a de formar. Sempre disponível, acessivel e aberto ao franco diálogo com seus alunos e alunas, ele formou gerações. Procurava sempre conhecer a fundo os dilemas, os problemas, as dificuldades profissionais e pessoais de seus alunos e alunas. Era mais do que um professor e orientador acadêmico. Era um conselheiro, um confidente, um companheiro, um amigo, "o amigo de sempre", como ele dizia.

Sua perseverança, tenacidade, disciplina e rigor metodológico o levaram ao ápice de sua carreira acadêmica em 1995, quando se tornou professor titular de Direito Internacional Público da Faculdade de Direito da Universidade de São Paulo, à qual se entregou e se dedicou de corpo e alma. Transformou-se, sem nenhum favor ou exagero. no maior especialista do Brasil e, quem sabe até, da América Latina, em Direito Internacional do Meio Ambiente. Aproveitou sua mais do que justa reintegração e breve retorno às atividades da carreira diplomática para refletir e concluir sua tese de titularidade, grande marco de sua vasta obra relativa ao meio ambiente internacional: "As Responsabilidades no Direito Internacional do Meio Ambiente" que deu origem ao já clássico livro Direito Internacional do Meio Ambiente: Emergência, Obrigações $e$ Responsabilidades.

Aliás, sempre o inquietou a questão da responsabilidade internacional. Tanto que seu primeiro livro tratou das "Salvaguardas nos Acordos Nucleares: BrasilEUA e Brasil-Alemanha"

Seu equilibrio, sua sensatez, seu espirito conciliador e de justiça também o tornaram um dos grandes e mais requisitados árbitros internacionais. Desempenhou, com brilhantismo, seu papel de árbitro do Mercosul. Sua obra traz uma enorme contribuição à compreensão desse mecanismo de solução de controvérsias. Seu artigo "Arbitragens ('omerciais Internacionais no Brasil: vicissitudes" é uma referência na doutrina brasileira sobre o assunto.

Com muito didatismo, soube trazer para a teoria sua vivência diplomática. Os livros Das Imunidades de Jurisdição e de Execução (tema de sua livre-docência) e 
Órgãos dos Estados nas Relações Internacionais: Formas da Diplomacia e as Imunidades de Jurisdição não deixam dúvidas disso. Foi, ademais, um dos grandes responsáveis pela criação do Curso de Relações Internacionais da USP, cuja primeira turma deverá formar-se muito em breve.

Sua extrema bondade e generosidade também levaram-no a ocupar-se dos Direitos Humanos. Além de artigos que publicou, tais como a "Celebração dos 50 anos da Declaração Universal dos Direitos Humanos: Sonhos e Realidade" esteve ultimamente empenhado na criação do primeiro curso de pós-graduação em Direitos Humanos, que está atualmente sendo oferecido pela USP

Seria, enfim, impossível em tão curto espaço de tempo falar sobre a obra e o legado tão grandiosos de nosso querido professor Guido. O que fica, acima de tudo, são as lições de vida ensinadas pelo saudoso mestre: lições de uma vida vivida com correição, caráter firme, honestidade intelectual, grandiosidade de espírito e bondade e generosidade extremas.

Suas lições de vida, aliás, poderiam ser muito bem resumidas na transcrição que the deixo como homenagem final de um poema de Fernando Pessoa:

"PARA SER GRANDE

Para ser grande, sê inteiro:

Nada teu exagera ou exclui.

Sê todo em cada coisa. Põe

quanto és no mínimo que fazes.

Assim, em cada lago a lua toda

brilha. Porque alta vive"

Obrigado, Professor Guido.

Curitiba, agosto de 2005. 


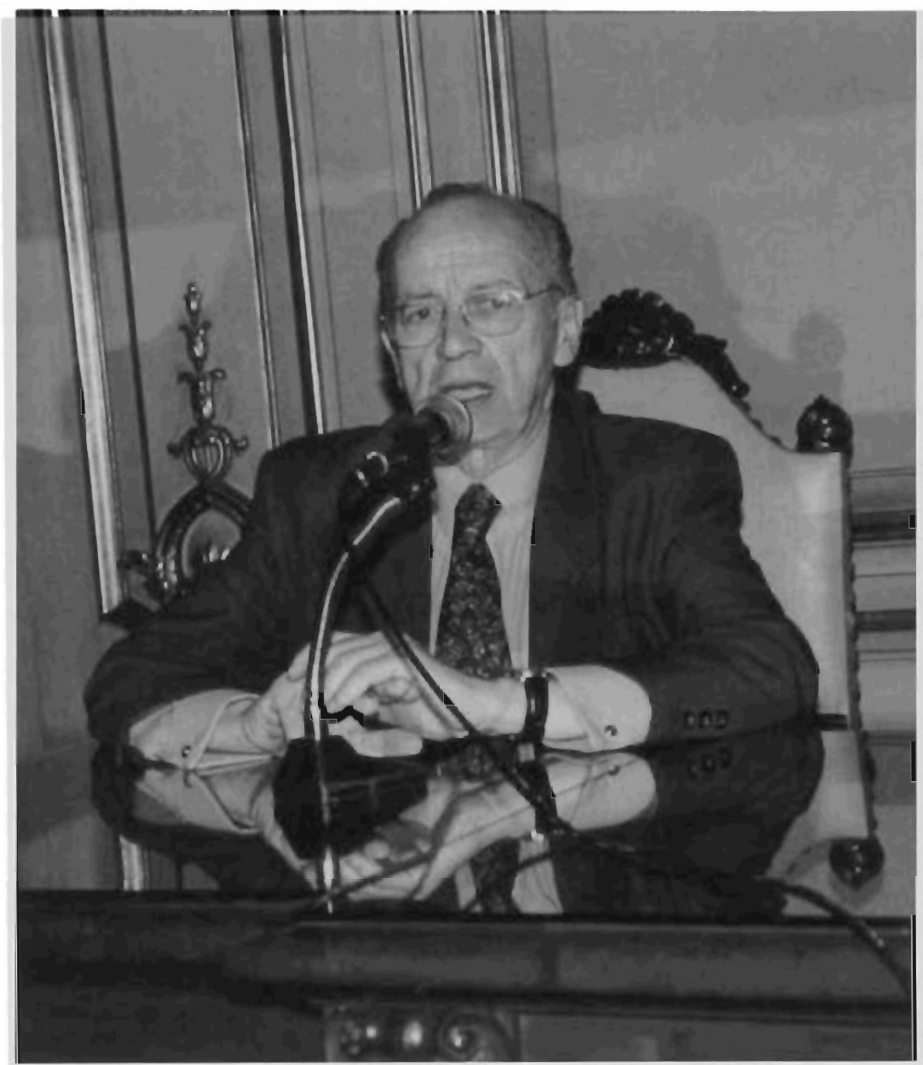

Professor Titular Guido Fernando Silva Soares 